\title{
PHOTOTOXICITY OF $\alpha$-TERTHIENYL AND PSORALENE INROSE AND MUSTARD APHIDS (MACROSIPHUM ROSAE \& LIPAPHIS ERYSIMI) IN DOON VALLEY
}

\author{
Sunil Kumar and Deepa Saini* \\ Department of Zoology, DAV (P. G.) College, Dehradun - 248001, Uttarakhand
}

*Corresponding Author Email id: deepasaini2109@gmail.com

Received: 20.11.2020; Revised: 4.12.2020; Accepted: 6.12.2020

(C) Society for Himalayan Action Research and Development

\begin{abstract}
Climate change has an impact on agriculture and insect pests that affect the crop production. Aphid pests occur throughout the temperate region of the world andcause direct damage by sucking plants sap which affects growth and yield of the crops. Species of aphids are diverse and ubiquitous but their importance among crop differs.Ultraviolet radiation (UVR) is an electromagnetic radiation and constitutes about $10 \%$ of the total light output of sunlight. Ultraviolet-B coming due to ozone depletion is the most photo chemically reactive wavelength of solar radiation and important stressor to organisms particularly in their early stages of life and affect ecosystem. Psoralene and alpha- terthienyl are naturally occurring plant metabolites found in many crops and become photo reactive in presence of solar ultraviolet- B radiation.

Measurement of solar ultraviolet radiation (UV-B and UV-E) was performed in Garhwalregion of Uttarakhand. Morphological, behavioural changes, mortality rate and glutathione contents were observed in mustard and roseaphids after ultraviolet-B irradiation with psoralene and $\alpha$-terthienyl photo sensitizers. UV-B and UV-E radiation showed seasonal, diurnal and altitudinal variations. $\alpha$ - terthienyland psoralenewith ultraviolet-B radiation showed stunted growth, morphological changes, low reproduction and high mortality up to $26 \%$ in aphids. Reduction in glutathione (GSH) level in aphids was also observed after UV- B and photosensitizersexposure.Enhanced UV-B was found more toxic with photosensitizers andthus, can be used as natural insecticide. Dose, intensity and species dependent changes in toxicity of psoralene and $\alpha$ - terthienyl were observed in aphids. Resultsindicate that UV-B radiation with photosensitizers has toxic effect on aphids population, dispersal and diversity. Psoralene was found more toxic than $\alpha$ - terthienyl in aphids. Mustard aphid (Lipaphis erysimi) was found more sensitive than rose aphid (Macrosiphum rosae).
\end{abstract}

Key words: Phototoxicity, Psoralene, $\alpha$ - terthienyl, Aphids, UV- index, Climate change

\section{Introduction}

Ultraviolet (UV) is an electromagnetic radiation with a wavelength from $200 \mathrm{~nm}$ to $400 \mathrm{~nm}$ and constitutes about $10 \%$ of the total light output of sunlight. Due to ozone depletion UV-B (280-315 $\mathrm{nm}$ ) is partly absorbed by the ozone layer and reaches the. Earth's surface. It has been reported that long- term exposure of humans to $\mathrm{UV}$ radiation may be very detrimental, inducing skin cancer, cataracts and weakening of immune functions (Diffey, 1996). Ultraviolet-B radiations coming as an outcome of ozone depletion to the
Earth's surface is the most photochemically reactive wavelength of solar radiation and important stressor to organisms particularly in their early stages of life. It shows a broad range of effect on biotic ecosystem.Erythema is the most common effect of an intense overexposure to UV radiation (UNEP, 2003). Nevertheless, UV radiation exposure is also beneficial for the health, for example, it contributes towards human Vitamin D synthesis (Webb et. al., 2006). The effects of UV-B on organisms depend on the dose 
of the harmful radiation to which an individualorganism is exposed. The deleterious effects of UV-B is enhanced and become more toxic, when organisms containing photosensitizers produces oxidative radicals.Different species of aphids (Homoptera: Aphididae) are cosmopolitan in distribution and found abundant in temperate climate and attack a wide variety of plants both cultivated and wild and may feed on roots, stems, leaves, inflorescence, fruits, and seeds (De Barro\& Carver, 1997). Temperature directly affects insects by altering their behaviour, metabolic rate and downstream cellular and physiological processes (Baleet al. 2007). Aphids feed on wide range of plants species and have a complex life cycle some of them are host alternating species while others live and multiply on particular host community whether these particular host plant species in anyway are associated with plant taxonomy. Aphids have a complex life cycle and involves many morphologically distinct forms and parthenogenesis generation alternating with asexual generation and in about $10 \%$ of species this is associated with host alternation (Foottit et al, 2008). Aphid pests occurs throughout the temperate region of the world, causes direct damage by sucking plants sap which affects growth and yield of the crops (Gulidov\&Poehling, 2013).

Psoralene and $\alpha$-terthienyl are naturally occurring metabolite found in many crop plants which shows adverse impacts on organisms in presence of ultraviolet. Climate change that is predicted to cause a global increase in temperatures andhigher UV-B radiation affect the dynamics of complex associations such as aphids and how they may respond to long term environmental changes (Hance et al., 2007). Direct UV-B radiation is another kind of abiotic stress that alters cellular integrity and damages DNA in most living organisms, which also affect aphid life cycle. Work on the potato aphid Macrosiphum euphorbiae did not reveal any direct effects of UV-B on reproduction (Nguyen et al., 2017). The primary source of bioactive vitamin $\mathrm{D}$ production in human skin upon solar UV-B (280-315nm) exposure; approximately $90 \%$ of circulating levels of vitamin $\mathrm{D}$ are attributed to sun light exposure (VoPham et al., 2017).Aphids are very small insects and usually poorly melanized, and hence potentially less protected against radiative stress. This study was designed to monitor UV-B and UV-E radiation in Doon valley, Garhwal region and to assess the impact of $\alpha$-terthienyl and psoralene photosensitizers on rose aphid(Macrosiphum rosae) and mustard aphid(Lipaphis erysimi)at different intensity of UV- B radiation.

\section{Methodology}

Study Area: Doon valley situated between $29^{\circ}$ $30^{\prime}$ to $31^{\circ}-28^{\prime}$ north latitude and $78^{\circ}-03^{\prime}$ to $78^{\circ}$ 32 ' east longitude was selected for the study. Aphid samples were collected form our Doon valley and reared in the laboratory. UV radiation (UV-B and UV-E) monitoring was done using Kipps and Zonen Radiometer, Netherlandhaving $312 \mathrm{~nm}$ spectral sensitivity. Data recorded were stored in Kipps and Zonen data logger (Logbox- SD). Data from different sites keeping in view of various factors such as season, altitude, latitude, weather condition and monthly variations were collected. UV monitoring was performed on clear sunny days at (600 msl- 1900 msl). Altitude and longitude measurements were done with the help of GPS Garmin USA.

Experimental protocol in aphids was designed using stock culture method (Hughes and Woolcock, 1965) and as modified by Tisher and Songlake (2001). Mesh netting cages were used for culture of aphids. Experiment was conducted in Dehradun. Rose aphid (Macrosiphum rosae) and mustard aphid (Lipaphis erysimi) were divided into 9 groups with two replicates. Group one was kept control, group two exposed to UV-B low dose, group three exposed with UV-B high dose, group four was given $\alpha$ - terthienyl, group five was given psoralene, group six exposed to $\alpha$ terthienyl + UV-B low dose, group seven exposed to $\alpha$ - terthienyl + UV-B high dose, group eight exposed to psoralene + UV-B low dose and group nine was exposed topsoralene + UV-B high 
dose.UV- B radiation of low intensity 0.690 $\mathrm{mw} / \mathrm{cm}^{2}$ and high intensity $900 \mathrm{mw} / \mathrm{cm}^{2}$ was given during experimental period in the months of February - March by Philips UV-B lamps. UV-B radiation was measured using Kipps and Zonen Radiometer.Experiment was performed for six days with daily exposure of 2 hour per day. $\alpha$ terthienyl (2,2':5',2"-terthiophene).. Psoralene (7H-furo[3,2-g]chromen-7-one) photosensitizes of Sigma Aldrich was used in the experiment. Concentration of photosensitizer used was $10 \mathrm{mg} /$ litre.Morphological, behavioural changes and mortality rate were recorded by the method (Wilkaniec et. al., 2017). Glutathione (GSH) is a small molecule, a tri-peptide made up of glutamic acid, glycine and cysteine and present in all known organism ranging from bacteria to humans. Glutathione redox status indicates the cellular reduction- oxidation state. It exists in free form mostly but it forms mixed- disulphide bond with co-enzyme A or cysteine. Total glutathione is determined spectrophotometrically by measuring absorbance at $405 \mathrm{~nm}$ (Beutler et. al., 1963). Statistical inferences were drawn by using Students' 't' test (Fisher, 1963).

\section{Results and Discussion}

The result on monitoring of solar UV- B radiation recorded in Garhwal region showed the highest value in month of June and minimum value in the month of January. The natural solar UV- B radiation level was recorded minimum at low altitude and increases with high altitude.The value of UV-B seen to increase from morning up to noon and then again seen to decrease gradually up to evening (Fig.-1).

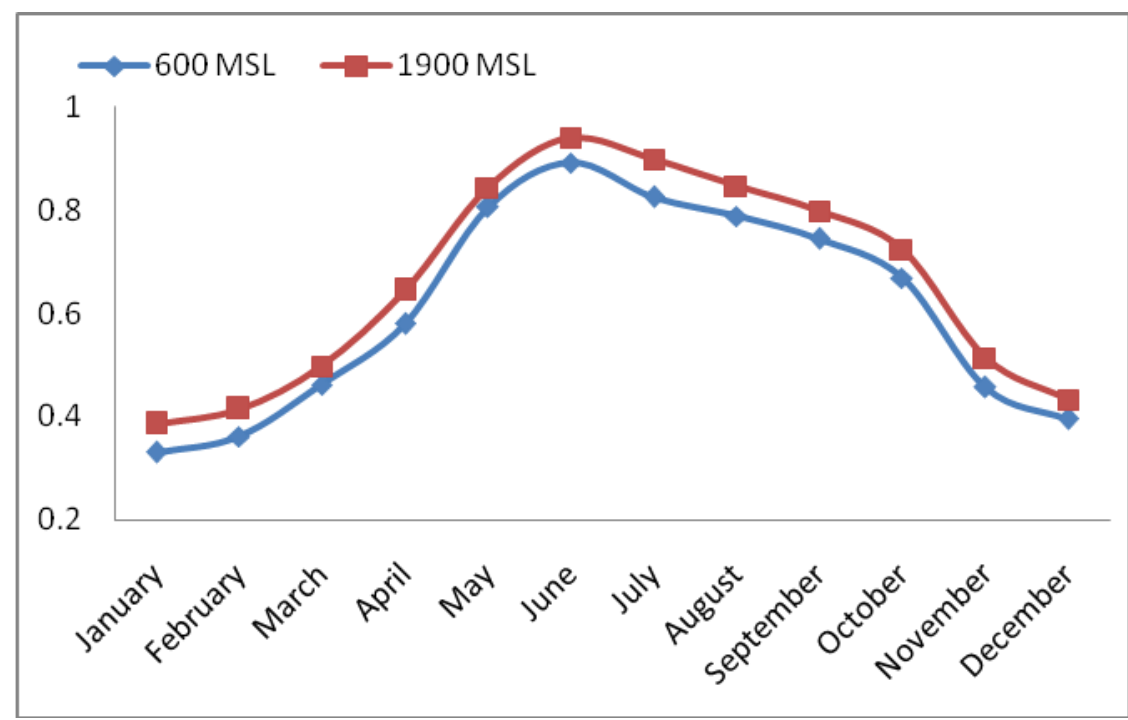

Figure 1: Seasonal Variation in Solar UV-B level at different altitudes in Garhwal region.

Solar UV- E radiation also measured every month depending on weather conditions UV-E intensity was found maximum at high altitudes and minimum at low altitudes in Garhwal region. The maximum value of UV- E was recorded in July and the minimum value was recorded in December. Slight altitudinal variation was observed in solar UV-E intensity (Fig.-2). 


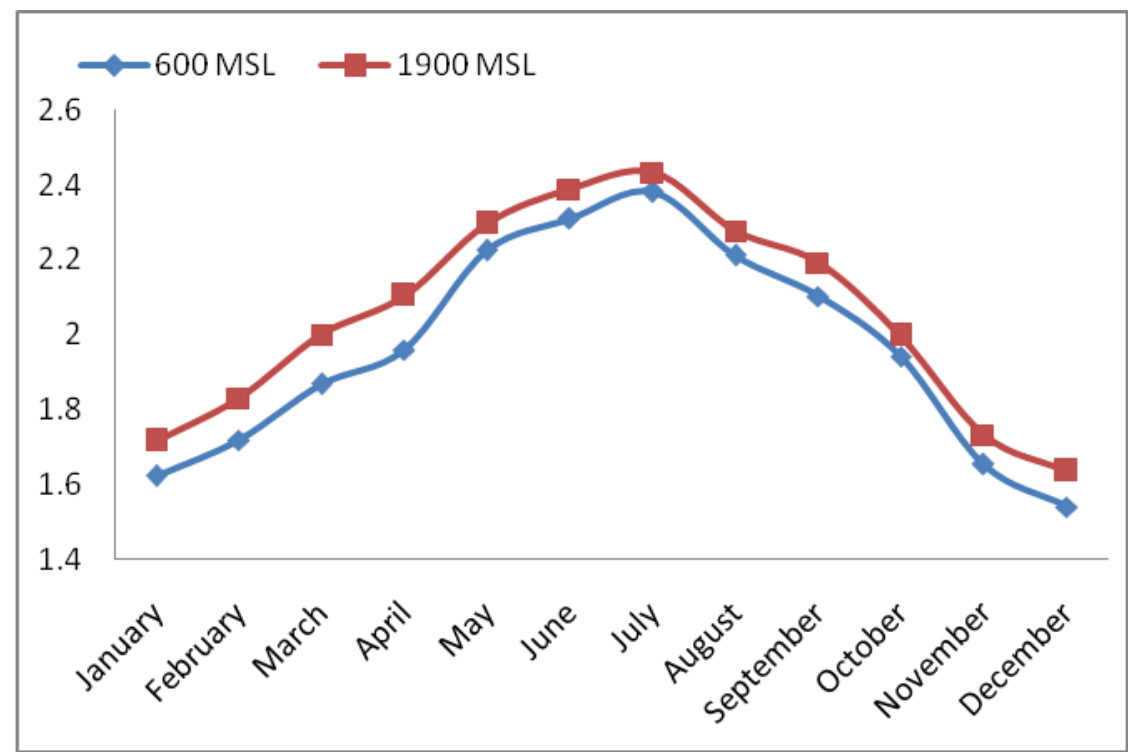

Figure 2: Seasonal variation in solar UV- E level at different altitudes in Garhwal region

Result on mortality rate in aphids indicates that increase in mortality in all the groups in comparison to control. Non- significant increase in mortality was observed after low intensity of UV-B or with individual exposure of photosensitizers. Highest mortality was reported after psoralene + UV-B high dose in Lipaphis erysimi followed by Macrosiphum rosae. $\alpha$ terthienyl was found less phototoxicity than psoralene. Enhanced UV-B intensity was found more toxic thus indicating dose/ intensity dependent toxicity in aphids (Table- 1).

Table 1: Mortality rate in Aphids with psoralene, $\alpha$-tertheinyl at low and high dose of UV-B radiation exposure

\begin{tabular}{|l|l|c|c|}
\hline S. No & \multicolumn{1}{|c|}{ Treatment } & Macrosiphum rosae & Lipaphis erysimi \\
\hline 1. & Control & $4 \pm 0.28$ & $4 \pm 0.29$ \\
\hline 2. & UV-B (low dose) & $6 \pm 0.45^{\mathrm{NS}}$ & $7 \pm 0.43^{\mathrm{NS}}$ \\
\hline 3. & UV-B (high dose) & $8 \pm 0.41^{\mathrm{NS}}$ & $9 \pm 0.49^{*}$ \\
\hline 4. & $\alpha$ - tertheinyl & $7 \pm 0.46^{\mathrm{NS}}$ & $8 \pm 0.47^{\mathrm{NS}}$ \\
\hline 5. & Psoralene & $8 \pm 0.75^{\mathrm{NS}}$ & $9 \pm 0.85^{*}$ \\
\hline 6. & $\alpha$-tertheinyl + UV-B (low dose) & $13 \pm 0.77^{*}$ & $15 \pm 0.87^{*}$ \\
\hline 7. & $\alpha$ - tertheinyl + UV-B (high dose) & $16 \pm 1.23^{*}$ & $19 \pm 1.89^{* *}$ \\
\hline 8. & Psoralene + UV-B (low dose) & $17 \pm 1.22^{* *}$ & $20 \pm 1.88^{* *}$ \\
\hline 9. & Psoralene + UV-B (high dose) & $22 \pm 1.56^{* *}$ & $26 \pm 2.25^{* *}$ \\
\hline
\end{tabular}

Results are mean \pm S. E. of 5 observations in each group. P- Value $<* 0.1, * * 0.01$,NS- non significant

Reduction in glutathione content GSH was observed in all the groups. Non- significant reduction in GSH was observed after individual exposure of UV-B and photosensitizers. UV-B and photosensitizer combined exposure cause photo toxicity and reduced the glutathione level significantly. Maximum radiation in glutathione was observed after psoralene + UV- B high dose in Lipaphis erysimy (Table- 2). 
Table 2: Reduced glutathione (GSH mg/g of tissue) in aphids at low and high dose of UV-B radiation exposure with $\alpha$ - terthienyland psoralene photosensitizers

\begin{tabular}{|l|l|c|c|}
\hline S. No & \multicolumn{1}{|c|}{ Treatment } & Macrosiphum rosae & Lipaphis erysimi \\
\hline 1. & Control & $910 \pm 0.83$ & $916 \pm 0.83$ \\
\hline 2. & UV-B (low dose) & $885 \pm 0.95^{\mathrm{NS}}$ & $880 \pm 0.94^{\mathrm{NS}}$ \\
\hline 3. & UV-B (high dose) & $838 \pm 2.46^{\mathrm{NS}}$ & $808 \pm 2.45^{*}$ \\
\hline 4. & $\alpha$ - tertheinyl & $905 \pm 2.46^{\mathrm{NS}}$ & $890 \pm 2.44^{\mathrm{NS}}$ \\
\hline 5. & Psoralene & $895 \mathrm{P} \pm 2.35^{\mathrm{NS}}$ & $875 \pm 2.34^{*}$ \\
\hline 6. & $\alpha$-tertheinyl + UV-B (low dose) & $822 \pm 2.77^{*}$ & $816 \pm 2.67^{*}$ \\
\hline 7. & $\alpha$-tertheinyl + UV-B (high dose) & $814 \pm 2.23^{*}$ & $795 \pm 3.19^{*}$ \\
\hline 8. & Psoralene + UV-B (low dose) & $790 \pm 3.22^{*}$ & $782 \pm 2.18^{*}$ \\
\hline 9. & Psoralene + UV-B (high dose) & $749 \pm 2.56^{* *}$ & $732 \pm 3.54^{* *}$ \\
\hline
\end{tabular}

Results are mean \pm S. E. of 5 observations in each group. P- Value $<* 0.1$, ** 0.01 ,NS- non significant

Morphological and behavioural changes were observed in aphids after photosensitizers and UV-B exposure (Fig.3-5).

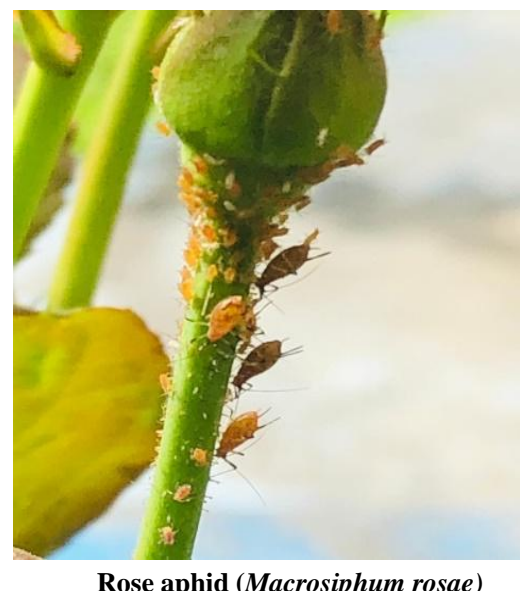

Rose aphid (Macrosiphum rosae)

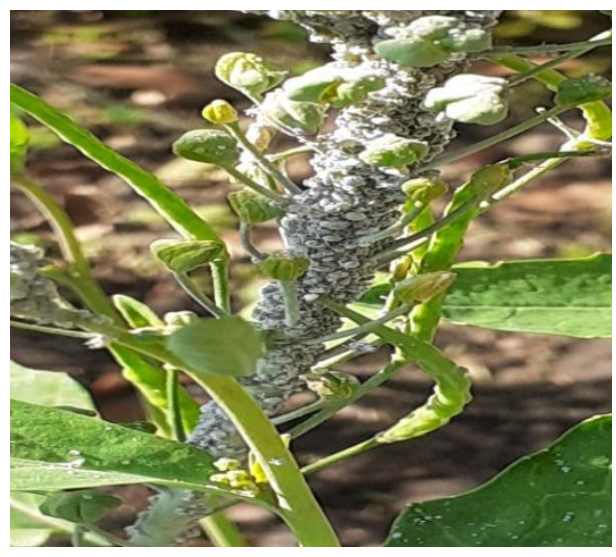

Mustard aphid (Lipaphis erysimi)

Figure 3: Rose aphid (Macrosiphum rosae) and mustard aphid (Lipaphis erysimi) in natural condition.

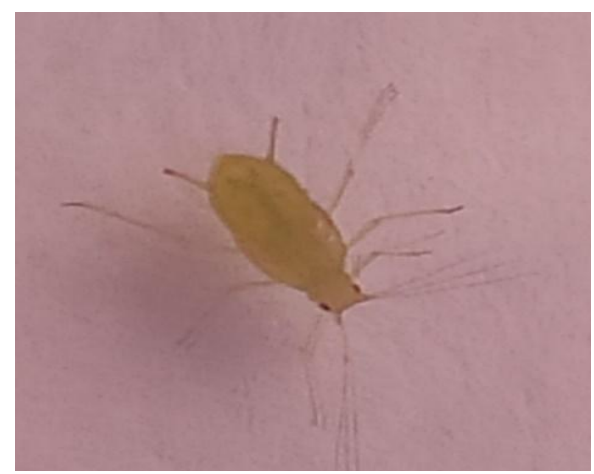

Macrosiphumrosae

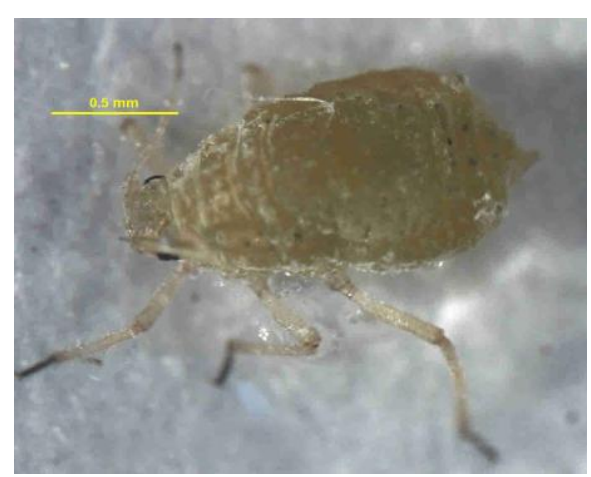

Lipaphiserysimi

Figure 4: Rose aphid (Macrosiphum rosae) and mustard aphid (Lipaphisery simi) before exposure. 


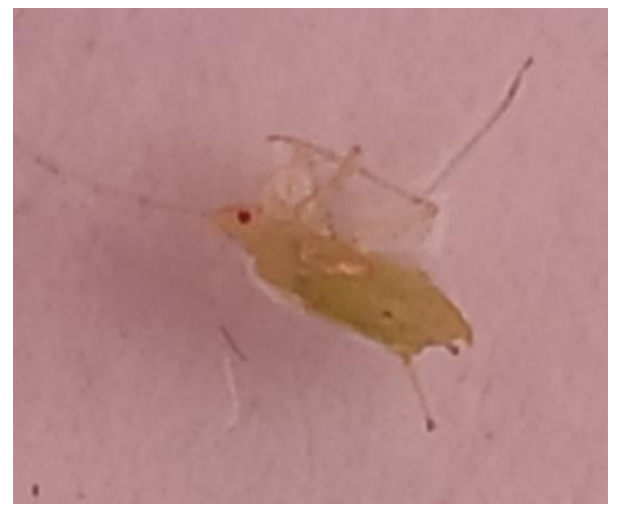

Macrosiphumrosae

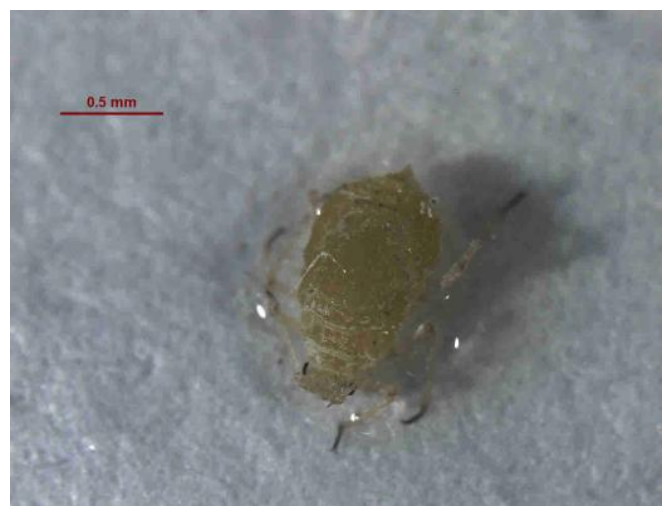

Lipaphiserysimi

Figure 5: Rose aphid (Macrosiphum rosae) and mustard aphid (Lipaphis erysimi) after exposure

According to evidences solar UV-Bis low at low altitude in winter season particularly in the month of January and February due to haze, fog, sun position, air mass and low intensity of sun exposure and solar ultraviolet UV-B highest in summer season in the month of July, August and September at high altitude due to clear weather, better sun exposure, air mass and position of sun ( Bornman et. al., 2019). Solar radiation is important abiotic stressor for aphid population. UV-B radiation can replace biochemical compounds in plants, which results in changes in the consumption of plants tissues by herbivorous insects and other animals.Aphid pests occurs throughout the temperate region of the world, causes direct damage by sucking plants sap which affects growth and yield of the crops. UVdeficient environments reduce winged aphids flight and reproduction ability, thereby reducing aphid propagation and dispersal rate within greenhouses (Legarreaet. al. 2012). Aphids stages were not counted separately because aphids density rather than stages structure of the aphid colony is the main factor influencing egg production and oviposition.

UV may interact with other dynamic drivers such as predation pressure to produce pattern in migration that vary seasonally and independently of UV exposure level. Photoenhanced toxicity may occur through two processes, photomodification and photosensitization. Photomodification is the structural modification of chemicals in water to more toxic/ reactive compounds. In photosensitization, the bioaccumulated chemical transfer light energy to other molecules causing cells damage observed in cyclops (Kumar et. al. 2016). Monitoring of solar ultraviolet-B radiation shows seasonal, diurnal and altitudinal variations, which continue to both the positive and negative effects of plants. For example, reduction in herbivore number was reported in UV-B- exposed willows. However, the letter result did not lead to increased herbivory. A review of numerous reports concluded that herbivory is generally reduced by UV-B radiation and it was also suggested that enhanced UV-B radiation may influence the predators of insect herbivores (UNEP, 2005). When exposed to near ultraviolet light, such as in sunlight, $\alpha$-terthienyl generates the toxic singlet oxygen. $\alpha$-terthienyl results in damage to the respiratory, digestive and nervous system of larvae, resulting in 100\% death rates in higher concentrations (Nivsarkar et. al., 2001). They also have use in photodynamic therapy, where the toxin is activated by intense light to destroy cancer cells.

Solar erythemal ultraviolet radiation (EUV) incident at the earth's surface is in the very low wavelength range, which is characterized by high photon energy and indicator UV- index. Excessive level of EUV is harmful to human, animals and other living organisms. In general, EUV is mainly controlled by stratospheric ozone, cloud cover and aerosols. High doses of EUV typical of tropical regions may have adverse effects on human health leading to increases in the risk of skin cancer, cataracts and suppression of the immune system. In addition, high exposure EUV has harmful 
effects on plant productivity, marine-ecosystems, biogeochemical cycles, air quality and degrades polymeric materials.High intensity UV induced changes and mortality in insects (arthropods) and cyclops reported (Kumar \& Kumari, 2011). Insect metabolism and physiology display a high degree of sensitivity to air temperature photoperiodism. Temperature most directly affects insects by altering behaviour and metabolic rate and downstream cellular and physiological processes (Bale et al. 2007). Impact of temperature and $\mathrm{CO}_{2}$ was observed in aphids morphology and behaviour (Rao et. al., 2016). Anti-oxidative responses of lepidopteron ovarian Tn5B1-4 and Sf-21 cells to photoactivated $\alpha$-terthienyl (PAT) are investigated (Huang et al, 2017). Skin cancer results the accumulation of mutations in genomic DNA that tare generated primarily by UV radiation. If DNA damaged cell is not properly redirected to apoptosis, the damaged bases can be replicated by error prone mechanism to give rise to mutations that drive the formation cancer (Dakup \& Gaddameedhi, 2017). $\alpha$-terthienyl occurs in the plant of Asteraceae family or found in abundance in the roots of Tagetes species and it is toxic to a number of insect species. It generates reactive oxygen species and has capacity to inhibit several enzymes.They become photoreactive in presence of Ultraviolet radiation(Bin et al. 2018).Non-significant decrease in reduced glutathione level was observed after exposure to UV-B low and high dose, Reduction in glutathione level occurs as an indication of decrease in anti-oxidative potential. $\alpha$ - terthienyl, a thiophene compound present in many plant species including marigolds can be developed as effective photoactivated insecticide (Luan et. al., 2018).Psoralene was found more phototoxic than $\alpha$ - tertheinyl for aphids. Mustard aphid was more sensitive than rose aphid as shown by high mortality. UV radiation with photosensitizer can be used in control of plant aphid pests.

\section{Acknowledgement}

Authors are thankful to Wadia Institute of Himalayan Geology, Dehradun and UGC New
Delhi No. F 43-562/2014 (SR) for instrumental support.

\section{References}

Bale JS, Masters GJ, Hodkinson ID, Awmack C, Benzemer TM, Brown VK, et al (2007) Herbivory in global climate change research: direct effects of rising temperature on insect herbivores. Glob. Chang. Biol. 8. 1.

Beutler E, Duron O and Kelly BM (1963) Improved method for the determination of glutathione. J. Lab. Clin. Med. 61: 882.

Bin Z., Jingqian H., Ning L., Zhang J. and Dong J. (2018).Trans ketolase is identified as a target of herbicidal substance $\alpha$-Terthienyl by Proteomics, Toxins, 10: 41.

Bornman, JF, Barnes PW, Robson, TM, Robinson, SA, Jansen MA, Ballaré, CL and Flint SD, (2019) Linkages between stratospheric ozone, UV radiation and climate change and their implications for terrestrial ecosystems. Photochem. Photobiol. Sci. 18(3): 681-716.

Wilkaniec B, Durak R and Borowiak-Sobkowiak, BB (2017) Morphology, biology and behavioral aspects of Aphis craccivora (Hemiptera: Aphididae) on Robinia pseudoacacia. Acta Sci Pol. Hortoru. 16(1):39-49.

Dakup P. and Gaddameedhi S. (2017).Impact of the circadian clock on UV - Induced DNA damage response and photocarcinogenesis. Photochem. Photobiol., 93: 296-303.

De Barro PJ and Carver M (1997) Cabbage whitefly, Aleyrodes proletella (L.) (Hemiptera: Aleyrodidae), Newly Discovered in Australia. Aust J. Entomol , 36: 255-256.

Diffey BL (1996) Solar ultraviolet radiation effects on biological systems, Phys. Med. Biol., 36, 3, 299-328.

Fisher RA (1963) Statistical method for research worker. Oliver and Boyd London. 119.

Foottit RG, Maw HEL, VonDohlen CD and Hebert PDN (2008) Species identification of aphids (Insecta: Hemiptera: Aphididae) through DNA barcodes. Mol. Ecol. Resour. 8. 1189-1201. 
Gulidov, S and Poehling HM (2013) Control of aphids and whiteflies on Brusseles sprouts by means of UV- absorbing plastic films. $J$. Plant Dis. Prot. 120 (3), 122-130.

Hance, T., van Baaren, J., Vernon, P. and Boivin, G., (2007). Impact of extreme temperatures on parasitoids in a climate change perspective. Annu. Rev. Entomol., 52, 107126.

Huanga Q, Yuna X, Raoa W and Xiaob C. (2017).Antioxidative cellular response of lepidopteran ovarian cells to photoactivated alpha-terthienyl. Pestic Biochem Physiol. 137, 1-7.

Hughes RD and Woolcock LT (1965) A modification of Johnson's method of rearing aphids, for ecological studies. New zeal j agr res, 8(3): 728-736.

Kumar S. and Kumari P. (2011).High intensity UV induced changes in aquatic arthropod with retene and riboflavin. Env. Con. J. $12,83$.

Kumar S, Choudhary N and Aara R (2016) Impact of temperature change and dissolved organic carbon on phototoxicity of photosensitizer on cyclops in Doon valley J. Mountain Res., 11, 15-21.

Legarrea S, Weintraub PG, Plaza M, Viñuela E and Fereres A, (2012) Dispersal of aphids, whiteflies and their natural enemies under photoselective nets. Bio. Control, 57(4), 523532.

Luan S, Muhayimana S, Xu J, Zhang X, Xiao C and Huang Q (2018) Photosensitization of Chinese hamster V79 cells to photoactivated alpha-terthienyl involving membrane damage and oxidative stress. J photoch photobio 185: pp.192-198.

Nguyen TTA, Michaud D, Cloutier C (2017) A proteomic analysis of the aphid Macrosiphum euphorbiae under heat and radiation stress. Insect Biochem Molec, 39, 20-30.

Nivsarkar, M., Cherian, B. and Padh, H., (2001). Alpha-terthienyl: a plant-derived new generation insecticide. Curr. Sci. 81 (6): $667-$ 672.
Rao S, M, Shaila O, Abdul Khadar B, Manimanjari D, Vennila S, Vanaja M, Rama Rao CA, Srinivas K, Maheswari $M$ and Srinivasa Rao C (2016) Impact of elevated $\mathrm{CO}_{2}$ and temperature on aphids. Research Bulletin, NICRA (01), 2061-2068.

Tisher C and Songlake (2001) Culturing Daphnia in eight easy steps. Aquaman. 10: 26- 32.

UNEP (2003). UNEP assessment reports: Environmental effects of ozone depletion and its interactions with climate change: 2002 assessment, Photochem. Photobiol. Sci., 2, 172.

UNEP (2005) Environmental Effects Assessment Panel, Environmental effects of ozone depletion and its interactions with climate change .Progress report, 2004, Photochem. Photobiol. Sci. 22, 177-184.

VoPham T, Bertrand KA, Yuan JM, Tamimi RM, Hart JE and Laden F (2017) Ambient ultraviolet radiation exposure and hepatocellular carcinoma incidence in the United States. Environ. Health, 16: 89- 95.

Webb A, Grobner J, and Blumthaler M (2006) Measuring Erythemally Weighted Irradiance. A Practical Guide to Operating Broadband Instruments. 92: 898.

$* * * * * * *$ 